INSTITUTE FOR DEFENSE ANALYSES

\title{
NATO Allied Joint Medical Publication 7: Allied Joint Medical Doctrine for Support to Chemical, Biological, Radiological, and Nuclear (CBRN) Defensive Operations, Final Draft
}

Carl A. Curling Julia K. Burr

July 2014

Approved for public release; distribution is unlimited.

IDA Paper NS P-5153

Log: H 14-000780 
The Institute for Defense Analyses is a non-profit corporation that operates three federally funded research and development centers to provide objective analyses of national security issues, particularly those requiring scientific and technical expertise, and conduct related research on other national challenges.

About This Publication

This work was conducted by the Institute for Defense Analyses under contract DASW01-04-C-0003, Task CA-6-3079, "CBRN Casualty Estimation Update of the Medical CBRN Defense Planning \& Response Project," for the Joint Staff, Joint Requirements Office for CBRN Defense and the U.S. Army Office of the Surgeon General. The views, opinions, and findings should not be construed as representing the official position of either the Department of Defense or the sponsoring organization.

Acknowledgments

The authors would like to thank Mr. James M. Demyanovich and Mr. Douglas P. Schultz for reviewing this paper.

Copyright

(C) 2014 Institute for Defense Analyses, 4850 Mark Center Drive, Alexandria, Virginia $22311-1882 \cdot(703) 845-2000$.

This material may be reproduced by or for the U.S. Government pursuant to the copyright license under the clause at DFARS 252.227-7013 (a)(16) [Jun 2013]. 
INSTITUTE FOR DEFENSE ANALYSES

IDA Paper NS P-5153

\section{NATO Allied Joint Medical Publication 7: Allied Joint Medical Doctrine for Support to Chemical, Biological, Radiological, and Nuclear (CBRN) Defensive Operations, Final Draft}

Carl A. Curling

Julia K. Burr 



\section{NATO STANDARD}

\section{AJMedP-7}

\section{ALLIED JOINT MEDICAL DOCTRINE FOR SUPPORT TO CHEMICAL, BIOLOGICAL, RADIOLOGICAL, AND NUCLEAR (CBRN) DEFENSIVE OPERATIONS}

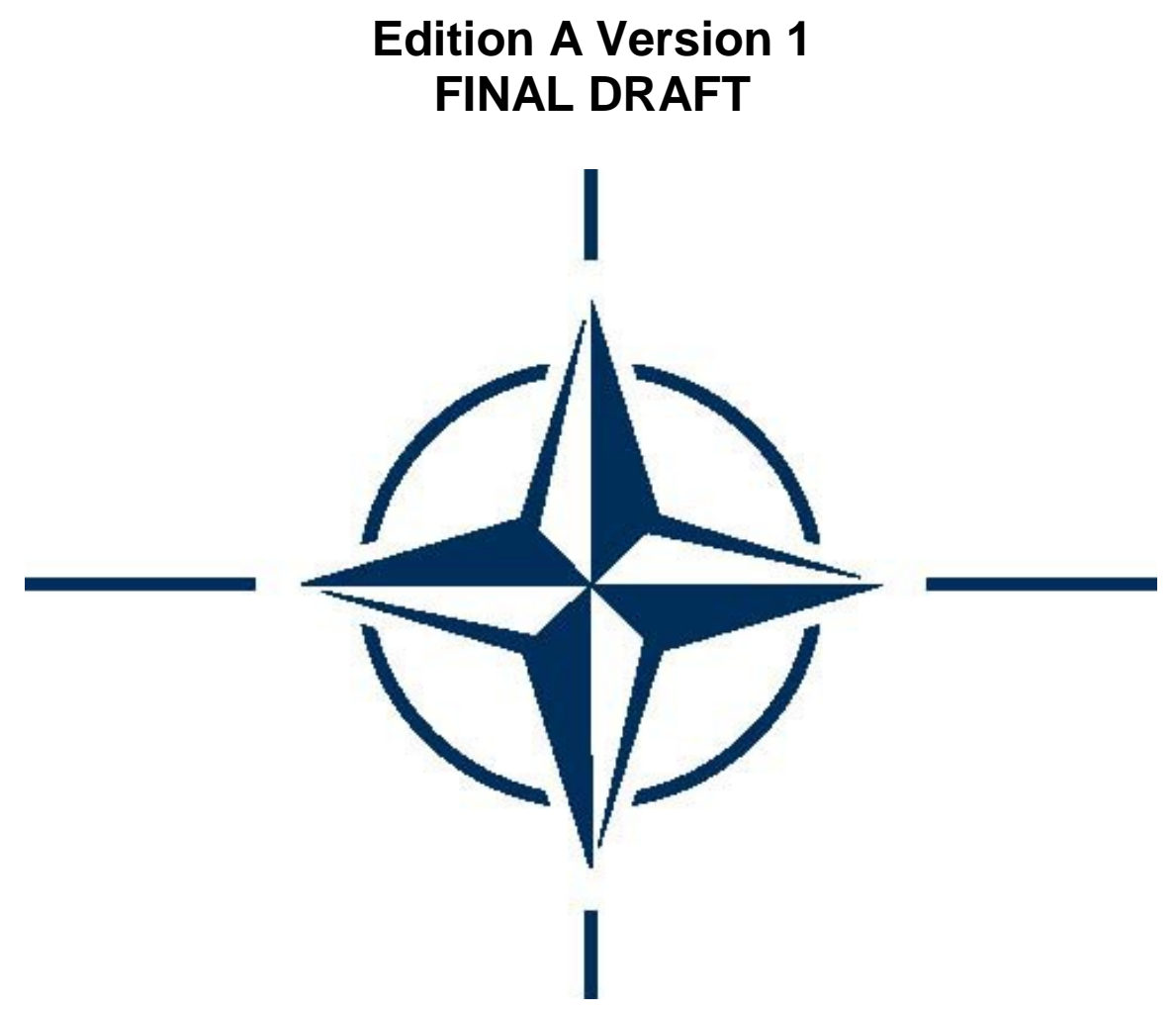

NORTH ATLANTIC TREATY ORGANIZATION

ALLIED JOINT MEDICAL PUBLICATION

Published by the

NATO STANDARDIZATION AGENCY (NSA)

(C) NATO/OTAN 
INTENTIONALLY BLANK 
NORTH ATLANTIC TREATY ORGANIZATION (NATO)

NATO STANDARDIZATION AGENCY (NSA)

NATO LETTER OF PROMULGATION

date

1. The enclosed Allied Joint Medical Publication AJMedP-7, Allied Joint Medical Doctrine for Support to CBRN Defensive Operations, which has been approved by the nations in the [TA], is promulgated herewith. The agreement of nations to use this publication is recorded in STANAG 2596.

2. AJMedP-7 is effective upon receipt/will come into effect on [NED].

3. No part of this publication may be reproduced, stored in a retrieval system, used commercially, adapted, or transmitted in any form or by any means, electronic, mechanical, photo-copying, recording or otherwise, without the prior permission of the publisher. With the exception of commercial sales, this does not apply to member nations and Partnership for Peace countries, or NATO commands and bodies.

4. This publication shall be handled in accordance with C-M(2002)60.

Dr Cihangir Aksit, TUR Civ

Director NATO Standardization Agency 
INTENTIONALLY BLANK 
AJMedP-7

RESERVED FOR NATIONAL LETTER OF PROMULGATION 
AJMedP-7

\section{INTENTIONALLY BLANK}


RECORD OF RESERVATIONS

\begin{tabular}{|c|c|}
\hline CHAPTER & RECORD OF RESERVATION BY NATIONS \\
\hline & \\
\hline & \\
\hline & \\
\hline & \\
\hline & \\
\hline & \\
\hline & \\
\hline & \\
\hline & \\
\hline & \\
\hline & \\
\hline & \\
\hline & \\
\hline & \\
\hline & \\
\hline & \\
\hline & \\
\hline & \\
\hline & - \\
\hline & 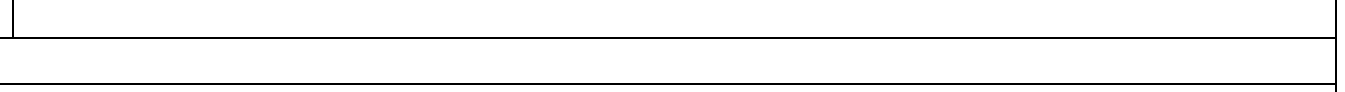 \\
\hline promulgat & $\begin{array}{l}\text { ations listed on this page include only those that were recorded at time of } \\
\text { may not be complete. Refer to the NATO Standardization Database for the } \\
\text { isting reservations. }\end{array}$ \\
\hline
\end{tabular}


AJMedP-7

INTENTIONALLY BLANK 


\section{RECORD OF SPECIFIC RESERVATIONS}

\begin{tabular}{|c|c|}
\hline [nation] & [detail of reservation] \\
\hline & \\
\hline & \\
\hline & \\
\hline & \\
\hline & \\
\hline & \\
\hline & \\
\hline & \\
\hline & \\
\hline & \\
\hline & \\
\hline & \\
\hline & \\
\hline & \\
\hline & \\
\hline & \\
\hline & \\
\hline & \\
\hline & {$\left[-{ }^{-}\right.$} \\
\hline & - \\
\hline & ( \\
\hline $\begin{array}{l}\text { ote: Th } \\
\text { romulga } \\
\text { omplete }\end{array}$ & $\begin{array}{l}\text { ions listed on this page include only those that were recorded at time of } \\
\text { nay not be complete. Refer to the NATO Standardization Database for the } \\
\text { ting reservations. }\end{array}$ \\
\hline
\end{tabular}


AJMedP-7

\section{INTENTIONALLY BLANK}




\section{TABLE OF CONTENTS}

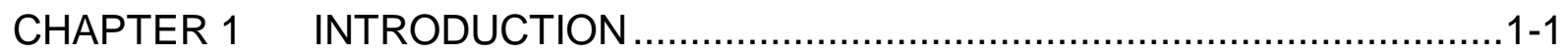

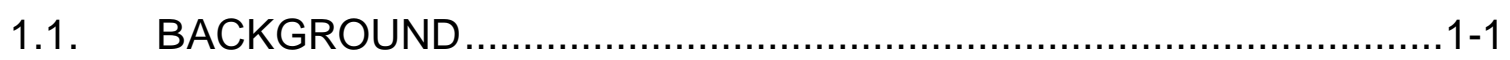

1.2. AIM …

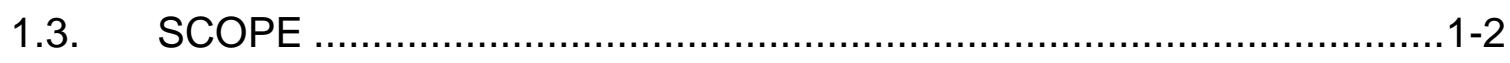

CHAPTER 2 MEDICAL CONTRIBUTION TO PLANNING AND EXECUTION OF OPERATIONS IN THE CBRN ENVIRONMENT …........................................... $2-1$

2.1. CHALLENGES OF THE CBRN ENVIRONMENT ..............................2-1

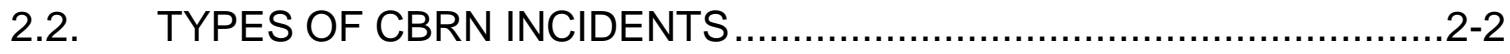

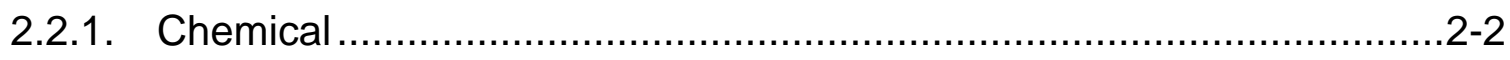

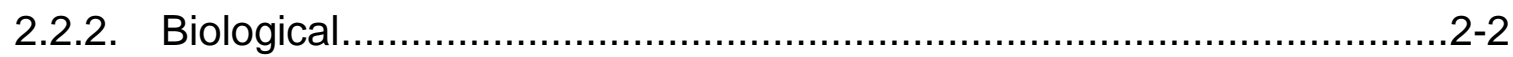

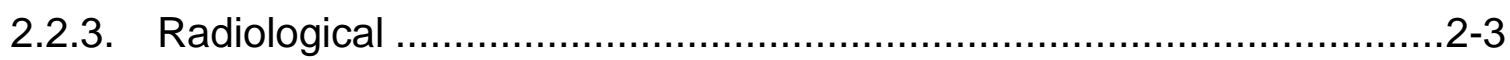

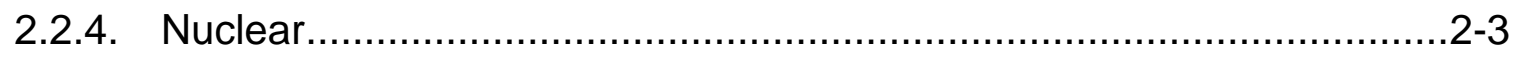

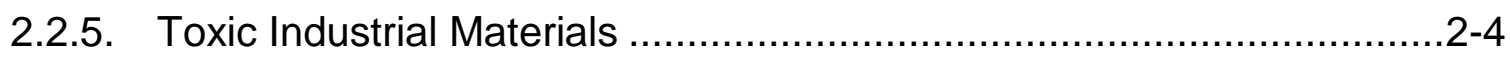

2.3. SCALE OF CBRN INCIDENTS AND CASUALTY MANAGEMENT ......2-4

2.4. MEDICAL CONTRIBUTION TO CBRN DEFENCE...........................2-5

2.5. THE ALLIANCE CONCEPT OF MEDICAL SUPPORT .......................2-5

2.6. PHASED MEDICAL SUPPORT TO CBRN DEFENCE OPERATIONS 2-6

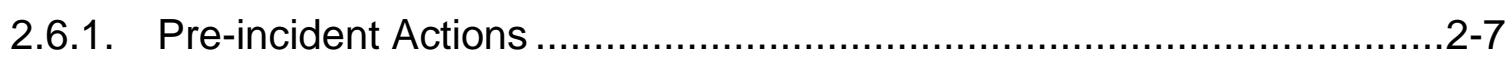

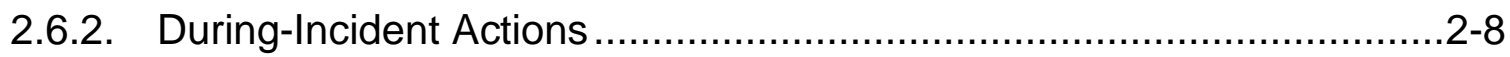

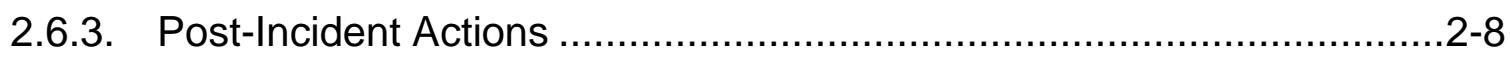

2.6.4. CBRN Medical Lessons Learned ............................................... 2-10

2.7. EDUCATION AND TRAINING FOR CBRN MEDICAL SUPPORT .....2-10

2.8. MEDICAL SUPPORT IN CBRN DEFENCE AGAINST TERRORISM .2-11

CHAPTER 3 SITUATIONAL AWARENESS AND CASUALTY ESTIMATION.....3-1

3.1. SITUATIONAL AWARENESS AND COMMAND AND CONTROL ........3-1

3.2. MEDICAL INTELLIGENCE JOINT INTELLIGENCE, SURVEILLANCE, AND RECONNAISSANCE (JISR) CAPABILITIES ……..............................

3.3. DEPLOYMENT HEALTH SURVEILLANCE ......................................

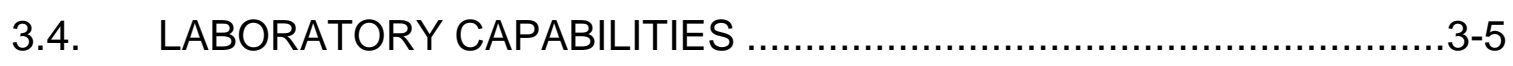

3.4.1. Medical Laboratory Support ……............................................

3.4.2. Non-medical Laboratory Support ……........................................

3.5. CBRN CASUALTY ESTIMATION ......................................................

CHAPTER $4 \quad$ FORCE HEALTH PROTECTION ........................................... $4-1$

4.1. HEALTH RISK ASSESSMENT AND HEALTH RISK COMMUNICATION4-1

4.2. PREVENTIVE MEDICINE SUPPORT ............................................4-2 


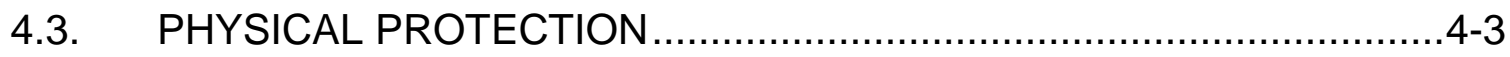

4.3.1. Individual Protection .......................................................

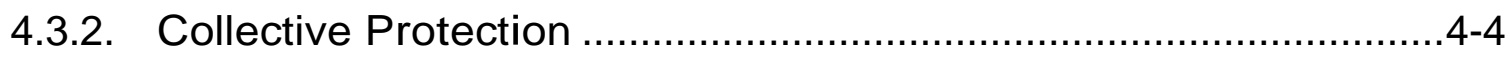

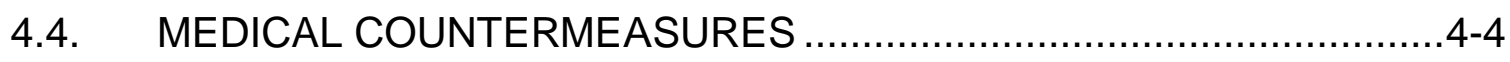

CHAPTER 5 CASUALTY MANAGEMENT AND HAzard Control.......................5-1

5.1. PRINCIPLES OF CBRN CASUALTY MANAGEMENT ......................5-1

5.2. HAZARD CONTROL MEASURES ............................................ $5-2$

5.2.1. Hazard Avoidance and Management ......................................... $5-2$

5.2.2. Operational Disease Control ................................................ $5-2$

5.2.3. Casualty Decontamination .................................................. $5-3$

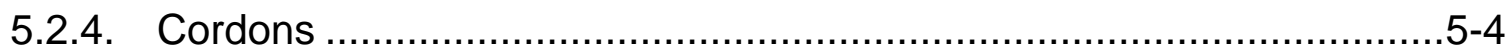

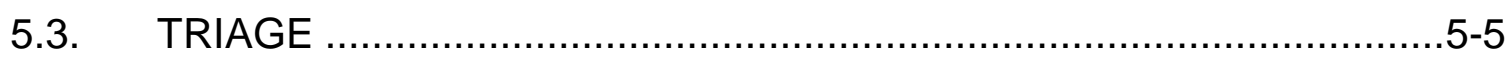

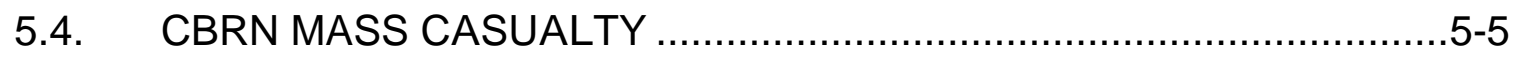

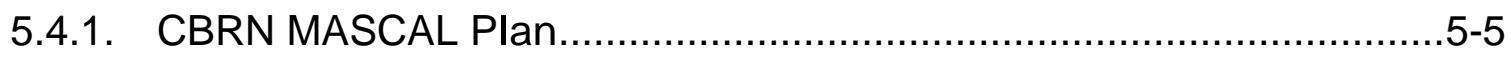

5.5. COMBAT AND OPERATIONAL STRESS CONTROL $\ldots \ldots \ldots \ldots \ldots \ldots \ldots . . \ldots-5$

CHAPTER 6 MEDICAL EVACUATION ................................................

6.1. MEDICAL EVACUATION POLICY AND OPERATIONS IN A CBRN

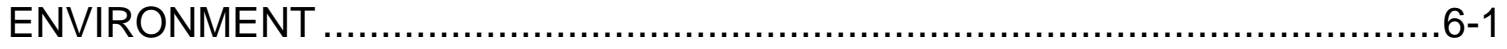

6.2. MEDICAL EVACUATION ASSETS IN A CBRN ENVIRONMENT ........6-3

6.2.1. Aeromedical Evacuation of CBRN Casualties..............................6-3

6.2.2. Movement of Contagious Disease Casualties ..............................6-4

6.2.3. Specialized National Evacuation Capabilities .................................6-4

CHAPTER 7 SUSTAINMENT OF MEDICAL OPERATIONS .........................

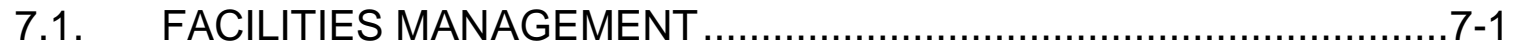

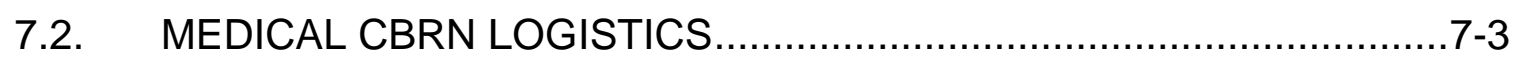

7.2.1. Management of Human Remains............................................

ANNEX A ACRONYMS AND ABBREVIATIONS .................................... A-1

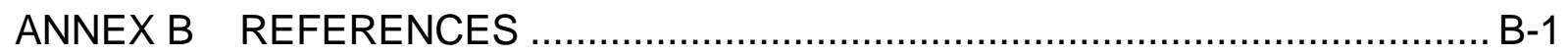

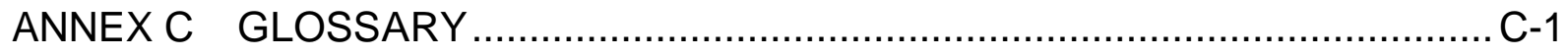




\section{CHAPTER 1 INTRODUCTION}

\subsection{BACKGROUND}

1. The mission of medical support in military operations is to preserve and restore troops' health and fighting strength and to minimize physical and mental disabilities. Medical support makes a major contribution to both force protection (FP) and mission accomplishment by the prevention of disease, rapid evacuation and treatment of the sick, wounded and injured and the return to duty of as many individuals as possible. The Joint Force Commander (JFC) directs medical capabilities and individual and unit health-related practices to prevent and/or correct any human condition that would impair or preclude the joint force from achieving its objectives. Medical support is employed across the range of military operations to enable the employment of healthy personnel. These capabilities span the operational environment from point of injury/illness to appropriate care.

2. The employment or threat of chemical, biological, radiological, and nuclear (CBRN) weapons and other toxic materials poses serious challenges to Allied military operations worldwide. CBRN incidents include the detonation of CBRN weapons and the accidental or deliberate release of chemical and biological warfare agents, toxic industrial materials (TIMs) (especially air and water poisons), biological pathogens, and radioactive material. The deadly, destructive, and disruptive effects of these weapons and materials merit continuous consideration by the JFC and supporting commanders.

3. Commanders at all levels are faced with the possibility that operations may have to be conducted in a CBRN environment, for either short or extended periods of time. Medical advisors are responsible for guiding and integrating all medical support capabilities available to the command to support mission accomplishment. Medical support operations in a CBRN environment of short duration may allow for some discretionary use of field expedients, while those of longer duration may demand significant augmentation of resources.

\subsection{AIM}

The aim of this publication is to provide medical planning doctrine for NATO multinational joint CBRN defence. STANAG 2437, AJP-01, Allied Joint Doctrine, provides the 'capstone' doctrine for the planning, execution and support of Allied joint operations. STANAG 2182, AJP-4, Allied Joint Doctrine for Logistics, provides doctrine for logistic functional planning. STANAG 2228, AJP-4.10, Allied Joint Medical Support Doctrine, provides medical support doctrine for NATO multinational 
joint operations and essential introduction for medical planning staffs. STANAG 2451, AJP-3.8, Allied Joint Doctrine for Chemical, Biological, Radiological, and Nuclear Defence, provides CBRN Defence doctrine for NATO multinational joint operations. AJMedP-7, as one of the supporting Joint Doctrine publications of AJP4.10, integrates the CBRN defence and medical support doctrine to provide the doctrine for medical support to NATO multinational joint CBRN operations and essential medical CBRN defence introduction for medical planning staffs.

\subsection{SCOPE}

1. Allied Joint Medical Support to CBRN Defensive Operations (AJMedP-7) has been developed in order to provide the framework for medical aspects of CBRN defence planning as well as for the operational planning process in all categories and at all levels of combined joint operations. This document is applicable to peace and the full spectrum of potential NATO operations (Article 5 as well as non-Article 5) from crisis through conflict.

2. This publication refers to Allied Joint Medical Support in a CBRN Environment; it provides a compilation of CBRN-specific medical planning considerations to supplement existing planning doctrine. It is amongst those Allied Joint Medical Publication (AJMedP) documents which are subsidiary to AJP-4.10 and which elucidate specific aspects of Allied Joint Medical Support doctrine. This publication does not reproduce the content of consolidated sources of doctrinal information, unless necessary for clarification or completeness. 


\section{CHAPTER 2 MEDICAL CONTRIBUTION TO PLANNING AND EXECUTION OF OPERATIONS IN THE CBRN ENVIRONMENT}

\subsection{CHALLENGES OF THE CBRN ENVIRONMENT}

1. The conduct of operations in a CBRN environment poses unique challenges to medical support forces worldwide. Preparations for medical support to CBRN defence operations must consider six such challenges:

a. The types of casualties from a CBRN incident are not those normally managed in a military medical support system;

b. The number of casualties resulting from CBRN incidents may exceed those normally managed in a military medical support system;

c. CBRN casualties may present abruptly with little or no warning. Indeed, CBRN casualties may be the first indicator of a clandestine CBRN attack;

d. CBRN casualties may be contaminated or contagious, and may constitute a significant hazard to the medical personnel, other patients, and facilities charged with caring for them;

e. Medical treatment facilities (MTFs) may have to operate in areas that are contaminated, or with restrictions that limit movement of personnel and materiel into, and out of, the MTF; such operations may require extensive use of individual and collective protection; and

f. Medical support will be required to continue for conventional casualties as well as for CBRN casualties.

2. Medical planning staffs face significant challenges in defining requirements for adequate medical force protection and the medical management of casualties in a CBRN environment. While these challenges are pervasive across medical support operations, CBRN-specific considerations are of particular relevance when dealing with the following components of medical support, each of which is discussed in detail in subsequent chapters:

a. Situational awareness (SA) and command and control (C2);

b. Casualty estimation;

c. Force health protection; 

d. Casualty management;
e. Medical evacuation; and
f. Sustainment of medical operations.

\subsection{TYPES OF CBRN INCIDENTS}

The near- and long-term medical impacts of CBRN incidents are a function of the type of attack and the scale of the incident. The impacts can be immediate, longterm, or a combination of the two. Regardless of the time frame, the medical impact will be a function of the five agent types:
a. Chemical;
b. Biological;
C. Radiological;
d. Nuclear; and
e. Toxic Industrial Materials.

\subsubsection{Chemical}

Depending on the agent and route of exposure, symptoms may appear almost immediately after exposure, or they may be delayed. For prompt casualties, the need for medical care is immediate and would potentially require a large and readily accessible antidote supply. Procedures for obtaining these antidotes must be well established. For casualties with delayed symptom onset, medical personnel will have a narrow window of time to prepare for expected casualties. In any chemical incident, follow-on casualties may occur from residual contamination in the initial hazard area or from migration of agent via pick-up and transfer. As discussed in Chapter 5, plans to move chemical casualties must account for the possible spread of contamination and mitigate it to the extent possible.

\subsubsection{Biological}

1. The time between exposure to a biological hazard and the onset of illness ranges from several hours to days or even weeks or months. The geographic size of areas where agent exposure will cause human effects varies greatly and is dependent on the agent properties, dissemination means, weather and proximity of exposed populations to the release. Consequently, if the agent can be detected 
quickly, it may be possible to avoid a substantial percentage of casualties via the administration of prophylaxis. On the other hand, if the agent is not detected until after casualties begin to occur, or if prophylaxis is not available for that agent, the potential for a large fraction of those exposed becoming casualties is increased. For some agents, a peak in casualties would take place within a few days and could quickly overload medical personnel and facilities. For others, peak incidence may occur much later, allowing more time for deliberate force augmentation, thus reducing the burden on existing personnel and facilities. In addition, aerosol releases of biological particulates may create a residual hazard in the environment or on equipment and clothing. Reaerosolization or contact with contaminated surfaces could generate follow-on casualties, exacerbating the burden on medical resources and extending it in time.

2. Naturally occurring or biological incident-induced contagious disease casualties create additional risk and induce special requirements for notification and control. As described in Chapter 5, there may be restrictions placed on the transportation of such casualties within a host nation or across international boundaries. They will also generate requirements for outbreak control, including restriction of movement (RM); these are discussed in Chapter 4.

\subsubsection{Radiological}

Mass casualties are unlikely to appear immediately unless the incident is also associated with intense radiation energy releases, explosions, or other conventional casualty producing scenarios. Penetrating radiation exposure symptoms are dependent on the dose rate and total dose. As in chemical incidents, contamination of casualties may occur from residual contamination in the initial hazard area or from migration of the radioactive material via pick-up and transfer. Unlike chemical warfare agent incidents with highly toxic materials, health impacting levels of radiation exposure may not coincide with immediate physical debilitation or obvious symptoms. The onset of symptoms from exposure to acute doses of radiation may be delayed for hours, days, or even weeks. These casualties may not have an immediate impact on operations but their numbers may increase over time based on initial and cumulative radiation exposures. Casualties with psychological effects, who may or may not also have radiation exposures, may appear at any time and have the potential to overwhelm medical facilities.

\subsubsection{Nuclear}

Casualties from nuclear weapons detonation effects will be both prompt and delayed. Prompt nuclear casualties will present with a combination of thermal, overpressure, trauma, and radiation injuries requiring immediate treatment. Casualties due to radiation alone may be delayed for an extended period of time, 
depending on the total dose. These include casualties from radioactive fallout. While the level of radiation in fallout is variable, it may be high enough to result in significant levels of cumulative radiation doses both where short exposures of high intensity fallout occur, and where there are longer durations of exposure to lower levels of radiation. Extended monitoring may be required for casualties not showing immediate symptoms.

\subsubsection{Toxic Industrial Materials}

TIMs are toxic substances used for industrial, commercial, medical, or domestic purposes. Though typically safely retained within manufacturing, storage, and transport facilities, such facilities may be both proximate to military operations and vulnerable to accidental or intentional release as a consequence of friendly action, adversary action, or accidents. Exposure to TIMs can have both short-term and long-term health effects, the nature and severity of which depends on the type of material and the quantity released.

\subsection{SCALE OF CBRN INCIDENTS AND CASUALTY MANAGEMENT}

1. CBRN incidents can vary greatly in magnitude. At the lower end of the scale, incidents such as the puncturing of a toxic chemical tank in the vicinity of an improvised explosive device can generate a small number of casualties requiring unusual but manageable medical care. These incidents are episodic in nature and typically can be managed within the regular medical planning process for conventional casualties. In the middle of the scale, Allied military forces may be required to conduct operations in a combat environment where the use of CBRN weapons is expected to occur with some level of frequency and intensity, commensurate with the ability of forces to mitigate effects of the CBRN threat. In such cases, medical planners must prepare to manage CBRN casualties as a routine part of medical support operations. At the upper end of the scale, CBRN incidents can result in disasters at a national or international level. Planning for these incidents should assume there will be mass casualty (MASCAL) events, complicated by potential CBRN contamination, and that resources and capabilities for response will be severely constrained.

2. Commanders and medical support planners must ensure that a process is in place to manage and treat CBRN casualties in a CBRN incident of any scale and across all phases of operations.. The widespread disruption and destruction that may accompany a large scale CBRN incident will require special casualty handling and will further challenge medical support capabilities and resources. To provide adequate medical support in these circumstances, definitive planning should be driven by pre- deployment intelligence collection, reporting, analyses, and risk 
assessments; these activities require close coordination among intelligence, CBRN defence, and medical staff officers.

\subsection{MEDICAL CONTRIBUTION TO CBRN DEFENCE}

AJP 3.8 divides CBRN defence into five enabling components: detection, identification and monitoring; information management; physical protection; hazard management; and medical countermeasures and support. The various components of medical support listed above contribute to each of these components of CBRN defence. Close coordination between medical and CBRN defence planning staffs is needed for effective planning in each of these areas. Such coordination allows exploitation of synergies among medical support and CBRN defence and ensures a holistic response to CBRN incidents. For example, CBRN defence operations can enhance medical support in a CBRN environment by providing early notification of the presence and nature of CBRN hazards and by limiting the number and severity of casualties through physical protection and hazard management. At the same time, medical identification and reporting of casualties or diseased animals or corpses may be the earliest indicators of a CBRN incident, and serve to launch all measures necessary for situation assessment.

\subsection{THE ALLIANCE CONCEPT OF MEDICAL SUPPORT}

1. Planning for medical support to NATO operations in a CBRN environment allows considerable flexibility. Though it does not reflect nor exclude any particular nation's approach to planning it does constitute a basic planning framework as a prerequisite for a common understanding in a joint and combined CBRN defence environment. AJMedP-7 is the primary source for medical planning for support to NATO CBRN defence operations within the NATO Command Structure.

2. The basic CBRN defence planning process remains the same across the range of military operations and occurs within and among all levels. Nevertheless, specific CBRN defence planning considerations may vary considerably among strategic-, operational-, and tactical-level operations due to differences in missions, perceived CBRN threats, available resources, and the size of the operational areas and area of interest. The use or the threat of use of CBRN weapons and/or the potential for accidental releases can cause large-scale shifts in strategic and operational objectives, phases, and courses of action. Planning at all levels should ensure the integration of CBRN considerations into the overall planning and decision- making processes. A key task for all commanders is the establishment of protection against CBRN attacks in the operational area and in other areas providing forces and sustaining capabilities. These goals include rapid and uninterrupted force preparation and deployment, and comprehensive force protection. 
3. Medical capabilities must be commensurate with the force strength and the assessed risks to the deployed forces. In a CBRN environment, medical support requirements may be greater in magnitude and different in kind than those needed to support conventional combat missions; this problem may be compounded by the combination of CBRN and conventional injuries, which may not be readily discerned or easily segregated. Planning for medical support in a CBRN environment must account for available medical protection and unique prophylaxis, diagnostic and treatment needs associated with the specific and plausible CBRN hazards indicated by medical and threat intelligence and risk assessments. It must also ensure that a surge capability is available to meet the numbers and types of casualties expected in operations where CBRN contingencies may exist.

\subsection{PHASED MEDICAL SUPPORT TO CBRN DEFENCE OPERATIONS}

1. Medical support is needed in all phases of operations, taking into account the unique characteristics and effects of the range of CBRN threats that may reasonably be encountered by employed NATO forces. While Allied policy and doctrine acknowledge that medical support is primarily a national responsibility, the medical advisor (command surgeon, surgeon general, or public health emergency officer) is responsible for guiding and integrating all medical support capabilities available to the JFC to support the mission.

2. AJP 3.8 highlights three distinct phases of a CBRN incident as it relates to CBRN defence, each of which has its own associated set of integrated medical and non-medical activities for which planning is required.

a. Pre-incident. Preparatory activities are fundamental to increasing the survivability of the force during a CBRN incident but some measures can degrade operational efficiency and therefore the commander's freedom of action. Effective risk management will allow the commander to achieve an appropriate balance. This means that pre-incident actions are not predefined but are a result of the CBRN intelligence assessments and other appropriate CBRN-related assessments, and are balanced against other threats to the force. During this phase, measures and available equipment are planned, assessed for sufficiency, prepared, tested, and, if necessary for some measures, implemented.

b. During-incident. If the appropriate CBRN measures were put in place preincident this will allow the force to be suitably protected immediately on warning of and during an incident whilst lowering the casualty number. This includes the avoidance of contamination, the relocation of units, the use of individual and collective protection, and immediate decontamination procedures. If suitable pre-incident measures were not established, then the commander is likely to have lost their freedom of action with the likely priority 
being survival rather than achieving the mission/objective.

c. Post-incident. These activities follow a CBRN incident and are essential to protect assets, restore operational capabilities and regain operating tempo. These measures will be performed to reduce the required level of protection and minimize the spread of contamination. These will include the operations necessary to determine the location, type and extent of the contamination, movement control to limit the spread of contamination, decontamination operations, and casualty care. Finally, the lessons learned process can be used to update and rapidly address observed shortfalls requiring immediate correction as well as apply them to longer term doctrine, procedures, and resource requirements.

\subsubsection{Pre-incident Actions}

1. In accordance with their missions, medical organizations assist in the CBRN information management domain by contributing to CBRN risk assessments based on integrated and updated Intelligence Preparation of the Operational Environment. They also assist with the CBRN force health protection domain by providing adequate shelter, establishing safe food and water sources, and ensuring that preventive measures and curative treatments are available to the forces they support.

2. Specific subjects to be included in pre-incident medical support planning need to address both CBRN information management, force health protection, and the establishment of medical treatment facilities. These subjects may include:

a. CBRN casualty estimation;

b. CBRN-related health risk assessment;

c. Deployment health surveillance assets;

d. Medical intelligence surveillance and reconnaissance assets, including the Rapidly Deployable Outbreak Investigation Team (RDOIT) and the Medical Radiological Incident Investigation Team (MRIIT);

e. Specific medical countermeasures;

f. MTF site selection;

g. Individual and collective protection;

h. Evacuation asset availability; and 
i. Casualty triage and decontamination planning.

3. Physical security and force protection measures may be needed at medical treatment facilities to permit sustained medical treatment. These measures and the assets needed to support them are provided by non-medical organizations and must be coordinated as part of pre-incident planning.

\subsubsection{During-Incident Actions}

The immediate response to a CBRN incident includes implementation of individual protection and-where available-collective protection necessary for the protection of the joint force during a CBRN incident that may involve localized, persistent or nonpersistent contamination and broad area, possibly transient, downwind hazards that develop following the incident. These need to be made ready and exercised in the pre-incident phase. Specific subjects that may need to be considered when planning to provide medical support during a CBRN incident are:

a. Implementation of individual and collective protection;

b. Establishment of casualty decontamination stations at casualty collection points;

c. Hazard avoidance;

d. Evacuation route planning; and

e. CBRN warning and reporting and information management.

\subsubsection{Post-Incident Actions}

1. Post-incident measures, necessary to limit the impact of CBRN incidents on operations, encompass mitigation, response, and recovery measures. The procedures, equipment and training necessary for effective CBRN warning and reporting, recovery and contamination control measures, hazard management and medical countermeasures and support need to be prepared for and practiced in the pre-incident phase.

2. Medical support planning for post-CBRN incidents must include efforts to conserve available medical support personnel for providing medical treatment and to promote the use of non-medical personnel to augment and support processes such as contamination control and casualty decontamination. Although most definitive care is rendered outside the area of immediate combat in a non-tactical environment, triage, casualty decontamination, and initial resuscitative care may need to be performed in the combat area. Medical operations within the combat 
area may be restricted due to significant hazards, including the presence of a persistent CBRN agent, explosive devices, effective enemy fired, environmental hazards, and personal protective equipment worn by responders and/or casualties; in such circumstances, medical care may be limited to first aid. Medical support planners must therefore coordinate with the relevant command staffs to ensure that units can locate clean areas in which to operate a medical treatment facility (MTF) or, if available, employ collective protection (COLPRO) shelter systems to provide life and limb care in combat areas. Commanders and ranking medical personnel must also plan to prevent or reduce the numbers of stress-related cases in this environment.

3. While planning for medical support after a CBRN incident includes many of the same considerations as planning for medical support generally, CBRN incidents may expand or alter these considerations. Specific subjects that may need to be considered when planning for medical support after a CBRN incident include:

a. Deployment health surveillance;

b. Utilization of operational epidemiology assets such as RDOIT and MRIIT

c. Utilization of national outreach, reach back and fusion, and forensic capabilities

d. Availability and utilization of laboratory assets with CBRN capabilities;

e. Post-exposure medical countermeasures

f. Mass casualty management;

g. Hazard management and contamination control, including casualty decontamination, exposure management, and restriction of movement;

h. Sustainment of medical support operations;

i. Management of contaminated human or animal remains, and contaminated waste management;

j. Public information; and

k. Post-incident recovery.

4. In the aftermath of a CBRN incident, medical support and public health service facilities may be strained beyond their capacities. Demands for medical support to both military and civilian populations could be intense. Medical support planning must assist the commander in establishing priorities and effectively using available medical support and public health service resources. To assure adequate support to 
the joint force, command directives concerning extent to which treatment is provided to civilian populations must be clear and adhered to by the Allied force medical support personnel and facilities.

\subsubsection{CBRN Medical Lessons Learned}

1. The Lessons Learned (LL) process begins in the post- -event recovery phase. The lessons learned (LL) process is a way to assure quality control for military operations by learning efficiently from experience, such as identifying gaps or shortfalls in capabilities (manpower, expertise, equipment, infrastructure, procedures) and by providing validated justification for amending the existing tactics, technics and procedures (TTP), as well as military requirements. Immediate assessment and coordinated feedback from the LL can further mitigate observed shortfalls in preparation for, response to, and recovery from the CBRN incidents.

2. CBRN medical lessons learned is led by Allied Command Transformation and is intended to improve medical support to operations in CBRN environments. The Medical Director within the JOA will provide the significant medical inputs, observations, data and information on behalf of the Joint Force Commander.

\subsection{EDUCATION AND TRAINING FOR CBRN MEDICAL SUPPORT}

1. As medical support in CBRN environments is particularly complex, medical personnel should undergo rigorous and frequent CBRN defence education and training programs. Such training will reduce the stress of CBRN incidents and improve operational effectiveness by educating medical personnel on appropriate response actions, including the use of IPE, recognition of individual and equipment contamination, execution of decontamination processes and procedures, and the conduct of operations in a collectively protected environment. It can also reinforce awareness of symptoms of CBRN exposure.

2. Medical personnel training standards for CBRN medical support are provided in STANAG 2954, AMedP-44, Training of Medical Personnel for CBRN Force Protection. Participating nations agree to use this document as the basis for training medical personnel deployed as part of a NATO operation. Its annexes provide recommendations for core training and special to role training for clinical and technical specialists and medical advisors. AMedP-44 recommends that individual refresher training and collective training be done at least every five years

3. Medical units are required to conduct CBRN exercises appropriate to their operational role and risk assessment at least every three years. All deploying expeditionary medical units are to exercise scenarios based on the current CBRN risk assessment. Multinational CBRN medical exercises have great value as a 
means of promoting interoperability through doctrine alignment and sharing/comparisons of tactics, techniques and procedures.

4. Additionally, medical support in CBRN environments should be integrated into exercises of CBRN defence operations and pre-deployment training in order to familiarize non-medical units and personnel with medical support capabilities and procedures.

\subsection{MEDICAL SUPPORT IN CBRN DEFENCE AGAINST TERRORISM}

1. MC 472, NATO Military Concept for Defence Against Terrorism (DAT), is the approved Alliance concept for dealing with the ongoing threat of large-scale terrorist attacks - to include those involving the use of CBRN-against member nations. Any such attack could quickly overwhelm even the most prepared nation(s). The DAT concept defines consequence management as, collectively, "the reactive measures used to mitigate the destructive effects of attacks, incidents or natural disasters," and further specifies a wide range of military support capabilities that the Alliance, if called upon, could provide to mitigate the effects of an attack.

2. Any NATO military medical response to a CBRN terrorist attack must be closely coordinated with national civil authorities, who retain responsibility for consequence management.

3. Specific issues in medical response to CBRN terrorist attacks are a function of the agent used but could include:

a. Casualty rates that are greater than those seen from conventional attacks, as the goal of the terrorist is often to inflict as many casualties as possible in the shortest period of time;

b. Clandestine attacks with biological or radiological agents, unnoticed until the end of incubation period and often masked under a variety of non-specific signs and symptoms;

c. Indirect casualties among the responders, as road traffic accidents, heat injuries, or psychological illnesses;

d. Medical support items and equipment provided by well-meaning individuals and organizations not fully appropriate for the incident. 
AJMedP-7

INTENTIONALLY BLANK 


\subsection{SITUATIONAL AWARENESS AND COMMAND AND CONTROL}

1. CBRN situational awareness (SA) and command and control (C2) play vital roles in supporting medical operations in a CBRN environment. SA belongs to the CBRN Information Management domain, one of the enabling components of CBRN defence. CBRN Information Management is the process of organizing, planning, staffing, directing, collecting, processing, validating, disseminating, displaying, reporting, exchanging, storing, maintaining and controlling CBRN-related information in order to obtain operational advantage. Timely processed and fused CBRN information and CBRN-related intelligence is a precondition for success while operating in a potential CBRN environment or under CBRN threat levels.

2. Especially important is a clear and commonly shared assessment of natural or anthropic CBRN threats within the Joint Operations Area (JOA), adversary CBRN capabilities, the effects and potential impact of CBRN incidents, national, multinational, and host nation medical support capabilities, and limitations or vulnerabilities in mitigating CBRN effects.

3. Effective SA and C2 are needed to quickly and correctly assess CBRN incidents and to provide the information needed to generate appropriate medical resources; this in turn supports sustained operational effectiveness of units, installations, medical facilities, and the populace after an incident occurs.

4. Among the key considerations discussed above in planning for medical support to CBRN defence operations, the most significant from the perspective of SA and C2 are that CBRN incidents may generate casualties that are unusual in number, typology, seasonality, etiology, topography, epidemiologically or historically, or in distribution in time or space. The medical support system must be aware of the potential for CBRN casualties, alert for identifying and reporting sentinel casualties of unobserved CBRN incidents, and capable of controlling and maintaining the medical support system in support of CBRN defence operations.

5. Although the source and means of exposure to CBRN agents/effect influence the incidence and severity of injuries, basic principles of prevention and treatment do not change. For instance, rapid detection and accurate identification of chemical, biological, or radiological hazards are needed to provide operationally relevant information to the commander and medical support units. The first indication of a biological incident or exposure to covert radiological or chemical attack may be the appearance of numerous casualties; differentiating these casualties from those resulting from endemic disease or accidental exposure to environmental hazards 
may prove challenging. This information allows the commander to mitigate effects on the force, facilitate adequate casualty management, and provide effective medical treatment.

6. The medical planning staff has specific responsibilities that support effective $\mathrm{SA}$ and $\mathrm{C} 2$ in a CBRN environment.

a. Evaluate the medical intelligence available, coordinate with CBRN defence and intelligence staff elements, and advise the commander and his staff on the potential CBRN-related health implications of the operating environment;

b. Prepare the medical risk assessment, including the risk of CBRN hazards, to support the overall operational risk assessment; and

c. Participate in and monitor the warning and reporting of potential and actual CBRN incidents and hazards into command and control systems, and provide commanders with medical advice on the means to minimize the health effects of lethal or incapacitating CBRN exposure to deployed forces.

7. Medical Intelligence (MEDINT), a functional discipline of intelligence, is a major component of CBRN Information Management. Effective preventive and curative medical support for the forces requires complete, timely, and accurate MEDINT products and their integration into overall theatre intelligence assessments and estimates. As described in STANAG 2547, AJMedP-3, Allied Joint Doctrine for Medical Intelligence, MEDINT supports the development of the Intelligence Preparation of the Operational Environment, a process that continues through all phases of the operation. In the pre-incident planning phase, MEDINT contributes to the determination of needed medical capabilities and the planning of appropriate force health protection measures that protect against assessed CBRN threats. These activities extend into during-incident response and post-incident recovery phases, consistent with the cyclical nature of intelligence operations, and are synchronized with the commander's decision-making and operational requirements.

8. MEDINT provides:

a. Analysis of endemic diseases (chronic endemic diseases and possible endemic outbreaks by frequency, type, severity).

b. Analysis of potential environmental health hazards. These hazards can be naturally occurring, including those related to air, water, soil quality and entomology, and man-made, including industrial sites, toxic waste sites, major transportation routes for a specific geographic location that could be an ongoing hazard to deployed forces or could become a health hazard if accidentally or intentionally destroyed; 
c. Medical CBRN threat analysis and vulnerability analysis. This is a continual process of evaluating and compiling available information to identify and prioritize threats. Threat analysis includes the evaluation of each identified CBRN threat and its potential impact on force health and operational capability, through the CBRN casualty estimation;

d. Early detection of probable/possible/suspected public health events of operational/international concern;

e. Analysis of foreign medical capabilities and capacities.

f. Modeling and simulation of environmental and epidemiological impact of CBRN incidents, in support of hazard prediction and risk assessment.

9. Since the effects of CBR agents may first occur in the local population, it is important for medical intelligence to maintain a continuous awareness of the local civilian disease trends and unique cases in order to quickly detect public health events of operational concern potentially linked to CBR casualties. Throughout the operation, deployed forces will be required to notify the unit medical staff of any intelligence which may affect medical readiness.

\subsection{MEDICAL INTELLIGENCE JOINT INTELLIGENCE, SURVEILLANCE, AND RECONNAISSANCE (JISR) CAPABILITIES}

As part of CBRN defence operations, MEDINT collection and analysis relies upon gathering and integrating information derived from both medical and non-medical sources. These include some critical capabilities, representing an integral part of preparing and directing the deployment of relevant medical countermeasures:

a. Detection, identification and monitoring activities, such as surveys, sensor data, Sampling and Identification of Biological, Chemical, and Radiological Agents (SIBCRA) team activities, deployment health surveillance, and laboratory test support;

b. Operational epidemiology, defined as the investigation of disease and injury resulting from known or suspected chemical, biological, radiological agents, performed by RDOIT and MRIIT teams.

\subsection{DEPLOYMENT HEALTH SURVEILLANCE}

1. Deployment health surveillance is an important component of monitoring and maintaining the health of deployed personnel where there is a risk of CBRN hazards. STANAG 2535, AMedP-4.1, Deployment Health Surveillance, provides policy and guidelines for the surveillance of the health of NATO Service members, 
including: identification of the population at risk; assessment of the health of this population through all phases of deployment; identification and assessment of potential health hazards; provision of advice to Commanders regarding health control options; implementation of health control measures; communication of hazards and control efforts to affected personnel; monitoring of controls; and management of health surveillance data.

2. Since the first indication of adversary use of chemical, biological, or radiological weapons may be the appearance of unusual numbers or types of casualties, the deployment health surveillance system has a critical role in providing the earliest possible indication of attack. It will also foster the understanding of ongoing health threats required to detect abnormal casualty rates that would be indicative of attack. Relevant epidemiological data include recorded symptoms, syndromes, results of diagnostic tests, known environmental exposures, and geographic position. As noted in AMedP-4.1, the recorded data must be classified according to agreed-upon NATO and National definitions.

3. As a detection and early warning tool, deployment health surveillance provides analytically based alerts to commanders that support mitigating courses of action, including the use of medical countermeasures, operational disease controls, and further epidemiological investigations. Health surveillance assessments that indicate possible CBRN incidents directly fulfill typical CBRN defence Commanders Critical Information Requirements for reporting and coordination amongst the JFC and staff.

4. Occupational and environmental health surveillance consists of the assessment and accounting of physical, chemical, biological, and radiological exposures occurring in the ambient operational environment. During the deployment phase of operations, this involves identification and monitoring of locations and activities that pose risks, including industrial or agricultural chemicals likely or known to be present at deployment sites, ambient air, soil and water quality, entomological hazards, and TIMs encountered during operations.

5. NATO has recently undertaken a number of initiatives designed to enhance Allied deployment health surveillance and to improve its ability to serve as early warning of CBRN incidents:

a. Full implementation of the NATO Medical Information and Coordination System (MEDICS) will provide requisite staff and technology to monitor public health phenomena across all phases of an operation;

b. The NATO Deployment Health Surveillance Capability (DHSC), subordinate to the Military Medicine Center of Excellence, will serve as a central hub for real-time health surveillance by electronically collecting medical information from MTFs within the JOA. 
c. The EpiNATO system is a NATO-sponsored morbidity monitoring system. The DHSC has been tasked with collecting and evaluating the EpiNATO reports periodically produced by MTFs.

d. The RDOIT and MRIIT teams are deployable ad hoc medical teams established to conduct investigations of reported disease outbreaks and radiological incidents. As part of their larger missions, these teams are designed with the capability to collect medical samples; they may eventually have the technical capability to collect relevant veterinary or environmental samples and refer them to designated reference laboratories. The timely deployment of the RDOIT and MRIIT capabilities supports rapid agent identification and casualty management. STANAG 2529, AMedP-7.7, Rapidly Deployable Outbreak Investigation Team (RDOIT) for Suspected Use of Biological Warfare Agents, and STANAG 2551, AMedP-7.4, Regulations for Establishment and Employment of MRIIT (Medical Radiological Incident Investigation Teams) establish the necessary framework for the creation and employment of these teams

6. In addition to providing early warning of exposure to CBRN, deployment health surveillance supports post-incident actions such as ongoing monitoring of personnel known or suspected of being exposed to CBRN, and provision of aftercare if needed.

\subsection{LABORATORY CAPABILITIES}

Laboratory capabilities are fundamental to the rapid and accurate identification of chemical, biological, and radiological agents in environmental and medical samples, and to the diagnosis of biological disease in casualties. These capabilities include technologies for sampling and analysis of CBRN contaminants in air, soil, water and food supplies as well as in medical samples.

\subsubsection{Medical Laboratory Support}

1. Medical laboratory capabilities of varying sophistication are available throughout the medical support system, including basic laboratory capabilities at Role 1 facilities and field laboratory capabilities at Role 2 facilities. Fixed laboratory capabilities at higher levels can support confirmatory evaluations and more extensive assessment of medical samples.

2. Medical laboratory facilities collect and analyze medical samples in support of diagnosis and treatment of illness in casualties at these facilities; they may not have the resources to assess samples of other types or in support of other missions. The contingent use of medical laboratory capabilities in support of CBRN agent 
detection and identification should be coordinated during the pre-deployment phase of operations.

3. National reference laboratories capable of advanced and forensic analysis may serve as a reach back and fusion capability for NATO investigation and sampling teams, allowing unambiguously identification of CBRN hazards. Planning for medical support in a CBRN environment should include advance coordination of deployed sampling capabilities with National or NATO reference laboratories capable of providing advanced and forensic-level analysis.

\subsubsection{Non-medical Laboratory Support}

1. STANAG 4632, Deployable NBC Analytical Laboratory, establishes capability standards for the NATO Deployable NBC Analytical Laboratories (NBC-AL) and provides guidance on its essential functions, capabilities, and equipment. The NBC$\mathrm{AL}$ is designed to provide environmental sampling and identification of chemical, biological, radiological and nuclear agents within a JOA.

2. Methodologies for environmental sampling and identification of chemical, biological and radiological agents are addressed by STANAG 4701, AEP-66, Handbook for the Sampling and Identification of Chemical, Biological and Radiological Warfare Agents (SIBCRA).

\subsection{CBRN CASUALTY ESTIMATION}

1. Based on available MEDINT and health risk assessments, operational planning staffs will generate estimates of casualties that could result from CBRN incidents within the JOA. CBRN casualties will present to the medical system differently than conventional trauma casualties and result in different medical requirements; therefore, the process for estimating CBRN casualties is different than that for conventional combat casualty estimation. A methodology for estimating casualties from a CBRN attack can be found in STANAG 2553, AMedP-8, NATO Planning Guide for the Estimation of CBRN Casualties. As with conventional combat casualty estimates, CBRN casualty estimates are then used for resource planning, assessments of CBRN defence requirements, logistical support requirements, determination of theatre holding policy, evacuation planning, etc. in CBRN contingencies.

2. The casualty estimation process described in AMedP-8 further allows planners to establish a level of injury severity that individuals must reach before being defined as casualties. This feature is intended to provide planners with the flexibility to consider the urgency of the mission when determining the point at which individuals will be removed from combat and entered into the medical system. 
3. Required inputs to the CBRN casualty estimation process include: characteristics of the postulated attack, including the type of agent involved, method of delivery, and quantity of agent released; estimates of the resulting dose/dosage/insult to individuals; and assumptions about the availability and use of shielding, warning and response, and physical protection.

4. The casualty estimation process is a planning start point used in absence of actual NATO operational experiences in CBRN environments. Operational CBRN experiences will necessarily induce changes and modifications to casualty estimation and other medical processes as actual CBRN experiences and lessons learned are obtained. 
AJMedP-7

INTENTIONALLY BLANK 


\section{CHAPTER 4 FORCE HEALTH PROTECTION}

1. STANAG 2561, AJMedP-4, Allied Joint Medical Force Health Protection Doctrine, defines Force Health Protection (FHP) as the sum of all efforts to reduce or eliminate the incidence of disease and non-battle injuries to enhance operational health readiness and combat effectiveness. FHP is intended to prevent disease and injury by minimizing the vulnerability of personnel to health threats and hazards.

2. FHP planning is a critical component of medical operations and will be uniquely challenging for the medical community in a CBRN environment. Among the most significant challenges for FHP is that CBRN casualties may be contaminated or contagious and may constitute a significant hazard to the medical personnel and facilities charged with caring for them. In addition, MTFs may have to operate in areas that are contaminated, or with restrictions that limit movement of personnel and materiel into, and out of, the facility.

3. FHP is one part of the larger force protection process, described in STANAG 2528, AJP-3.14, Allied Joint Doctrine for Force Protection. The components of the FHP process described in this chapter align with the components of Force Protection as follows:

a. Health Risk Assessment is part of Risk Assessment

b. Preventive Medicine Support is part of Risk Management

c. Physical Protection and Medical Countermeasures are part of Incident Response and Recovery.

4. FHP measures are essential parts of the planning process and their implementation begins during the pre-deployment phase, continues throughout the deployment and must extend well in the post-deployment period. FHP capabilities unique to CBRN include physical protection and specific medical countermeasures, including vaccines, pre- exposure prophylaxis, and post-exposure prophylaxis. Further guidance on the use of FHP measures in support of CBRN defence operations can be found in STANAG 2873, AMedP-7, Concept of Operations of Medical Support in Chemical, Biological, Radiological, and Nuclear Environments.

\subsection{HEALTH RISK ASSESSMENT AND HEALTH RISK COMMUNICATION}

1. STANAG 2535, AMedP-4.1, Deployment Health Surveillance, provides current NATO policy and guidelines for the conduct of health risk assessments. The FHP staff, in cooperation with MEDINT and with the medical planning staff, prepares the 
health risk assessment. This assessment is based on environmental health hazard and threat assessment, as well on environmental, occupational and disease surveillance information related to the JOA.

2. AMedP-4.1 further provides general policy and guidelines for health risk communication. In a CBRN environment, the communication of CBRN health risks and information in an accurate and timely manner is a critical enabling component of operations in a CBRN environment and a prerequisite for successful control of health risks.

3. Any probable or confirmed CBRN incident within a JOA may result in a Public Health Emergency of International Concern as defined by the 2005 International Health Regulations. In such cases, the JFC, with the assistance of the medical advisor, may be obligated to report the incident to the World Health Organization using designated channels of communication. Reporting obligations and processes should be established during the pre-incident phase of operations.

\subsection{PREVENTIVE MEDICINE SUPPORT}

1. Preventive medicine specialists play an important role in assessing and mitigating the medical threat posed by a CBRN incident. They can assess CBRN health risks and determine, in a comprehensive and integrated manner, the required use of FHP capabilities in managing those risks. Relevant capabilities include:

a. Physical protection (individual and collective);

b. Specific medical countermeasures; and

c. Combat and operational stress control.

2. Adherence to both the principles of preventive medicine and public health standards can mitigate the effects of CBRN incidents, particularly if these are implemented before an incident involving contagious organisms or toxic contaminants. Timely and effective application of preventive medicine principles can reduce the hazard to the medical personnel and facilities by preventing the spread of contamination or contagion.

3. Following any CBRN attack, special emphasis should be placed upon sanitation, hygiene, and common prevention measures that reduce the spread of disease. Carelessness in emergency situations regarding sanitation, general hygiene, and other common disease control measures can significantly contribute to secondary spread of disease. Enforcing satisfactory personal hygiene and field sanitation is a leadership responsibility. All personnel must apply standard, individual hygiene and sanitation measures. 
4. Maintaining safe food and water supplies is vital in all environments, and becomes more complex in CBRN environments due to the potential for contamination. Protective measures must be practiced by those who transport, store, prepare, and serve food as well as by those who consume the food. In addition, commanders must consider applying control measures to prevent contamination of food by insects, rodents, and other vectors. Insect and rodent control becomes more important following a CBRN attack because they may become vectors.

5. Rigid enforcement of water sanitation measures may reduce the spread of contamination or contagion. Strict procedures are required for waste treatment and sewage, including water surveillance and sanitation control measures. In all cases, the designated medical authorities must control and approve all water supplies before distribution and consumption. STANAG 2136, AMedP-4.9, Requirements forWater Potability during Field Operations and in Emergency Situations, provides the minimum requirements for water potability during all field operations and in emergency situations.

\subsection{PHYSICAL PROTECTION}

MTF commanders are responsible for determining the appropriate degree of CBRN physical protection, based on their assessment of local conditions. Suitable guidance for the use of physical protection can be found in AJP-3.8. CBRN physical protection can be applied individually or collectively. IPE and/or COLPRO enhance survival of medical personnel and casualties in the aftermath of CBRN incidents and allow operations to continue in a CBRN hazard environment. Individual physical protection can reduce operational capability due to physical burdens of heat stress and wear on people. Collective protection allows unencumbered work to continue but is reliant upon effective contamination controls and a deliberate and slow process for entry. Therefore, commanders must reconcile the vulnerability of personnel to CBRN hazards with the restrictions imposed by the use of protective measures and the need to pursue the mission.

\subsubsection{Individual Protection}

1. Individual protection is defined as that protection provided to an individual in a CBRN environment by protective clothing and/or personal equipment. All military personnel within the population at risk should be provided with IPE, consisting of an individual respiratory protection system (respirator or mask), protective clothing, prophylaxis/pre-treatment medications as needed, emergency antidotes, an individual decontamination kit, and a first aid kit.

2. IPE commonly used by military forces is not usually designed to protect 
against TIMs. When there is a risk of TIM exposure, professional assessment by specialized CBRN units and preventive medicine personnel-industrial hygienists, toxicologists, and occupational and/or environmental specialists-can ensure reasonable exposure guidelines and appropriate use of protective equipment. While some units may be able to conduct such assessments in the field, others may need to rely on reach-back capabilities, either within their home nation or within NATO.

\subsubsection{Collective Protection}

1. CBRN COLPRO systems offer more polyvalent protection than individual protective equipment and provide personnel with a CBRN hazard-free environment for performing critical work and obtaining rest and relief in order to sustain combat operations. This facilitates the continued performance of operational functions without the psychological and physiological effects that result from the extended use of individual protective equipment. This objective may be satisfied by the selective employment of fixed, mobile, transportable or hybrid CBRN COLPRO. These capabilities and guidance for their use are described in AJP-3.8.

2. MTFs in particular may benefit from the use of COLPRO and associated contamination control measures to protect both medical personnel and casualties from CBRN exposure via contaminated individuals, equipment, proximate casualty decontamination facilities, or migration of the hazard.

\subsection{MEDICAL COUNTERMEASURES}

1. Medical countermeasures are medical interventions designed to diminish the susceptibility of personnel to the lethal and damaging effects of chemical, biological and radiological hazards and to treat any injuries arising from exposure to such hazards. Commanders and staffs need to make decisions, on advice from the medical staff, about the timely and appropriate administration of medical countermeasures. This advice is supported by the pre-deployment health risk assessment, ongoing MEDINT operations, and the threat assessments conducted by intelligence and CBRN force protection elements. Medical countermeasures must be issued to personnel under national guidelines.

2. Medical countermeasures are of four general types:

a. Pre-exposure prophylaxis, which includes vaccinations and pharmaceuticals administered to personnel before the detection of an exposure in order to prevent the effects of a CBRN agent;

b. Pre-treatment, the administration of therapy enhancers before the exposure in order to enhance the post-exposure prophylaxis; 
c. Post-exposure prophylaxis, used after an exposure has been detected in order to prevent or minimize the effects of CBRN agents;

d. Immediate therapy, used to treat the initial effects of a CBRN agent based upon signs and symptoms.

3. Commanders should ensure that all personnel have been given appropriate medical countermeasures, according to national standards. These include up-todate immunizations, other required prophylaxis, and/or designated medical barrier materials (skin barrier sprays or repellents) as ordered before entering a potential CBRN hazardous area. Medical support personnel will assist commanders by ensuring that all exposed personnel receive appropriate medical countermeasures as required throughout the during-incident and post-incident phases of CBRN defence operations. 
AJMedP-7

\section{INTENTIONALLY BLANK}




\section{CHAPTER 5 CASUALTY MANAGEMENT AND HAZARD CONTROL}

1. Casualty management refers to a group of post-incident medical capabilities that are used to preserve the health of the force, to deliver optimal care to casualties, and to maximize the rate at which casualties return to duty. In the aftermath of a CBRN incident, the number of casualties may far exceed the capacity of the medical treatment system. The medical planning staff must develop a plan for managing a substantial increase in casualty flow and the demand for treatment. The plan must address handling and movement of CBRN casualties, including those that are contaminated or contagious; limiting contamination spread; and treating the wide range of CBRN injuries and illnesses. CBRN casualty care requires a continuum of care from point of exposure to Role 4 MTFs, with extensive coordination and negotiation with contributing nations and the host nation.

2. Among the key considerations discussed above in planning for medical support to CBRN defence operations, the most significant from the perspective of casualty management are: that CBRN incidents may produce a large number of casualties; that the types of casualties from a CBRN incident are not those normally managed in a military medical support system; and that CBRN casualties may be contaminated or contagious. CBRN incidents can generate large numbers of casualties who have been exposed to chemicals, infectious disease, toxins, or radiation. Medical facilities should be prepared to respond rapidly as casualty workload will likely peak quickly with little advance warning. As some infections caused by biological agents are transmissible between humans, they may cause problems for some time after any initial attack.

3. Efficient CBRN casualty management requires patient tracking and regulating in a standardized and interoperable format throughout the theatre of operations and in all national contingents. This includes management of medical information regarding individual casualties, availability of treatment, and evacuation assets.

\subsection{PRINCIPLES OF CBRN CASUALTY MANAGEMENT}

The general principles of casualty management should be extended to CBRN casualties. However, as described in AMedP-7.1, CBRN casualties may have treatment needs that are significantly different than those of conventional casualties. Normally, conventional medical capabilities and MTFs may not have the personnel, equipment, pharmaceuticals, and materiel needed to support these casualties, particularly in a mass casualty situation. Account of requirements for CBRN casualty management must be made during medical planning, given the particular threat. AMedP-7.1 describes treatment and other medical support requirements for casualties suffering from CBRN-related illness and injury. 


\subsection{HAZARD CONTROL MEASURES}

\subsubsection{Hazard Avoidance and Management}

1. In the pre-incident phase, the avoidance of potential CBRN contamination will be a key factor in planning for the location of medical facilities. In the during- and post-incident phases, medical facilities may need to be relocated to avoid contamination, such as from the arrival of nuclear fallout or the passing of a biological agent cloud. Guidance on the management of medical treatment facilities and the sustainment of operations in a CBRN environment is provided in Chapter 7.

2. In the event hazard avoidance is not possible and contamination occurs or is ongoing, medical support elements must be capable of sustaining operations. All required health services must continue to be provided, including caring for CBRN casualties. Because of the unique and significant burdens associated with sustainment of operations in a CBRN environment, such as the need for individual protective equipment, training and exercises are crucial for effective accomplishment of the medical mission.

3. Implementation of CBRN hazard avoidance and hazard management activities should be based on military exposure guidelines, as available, and should, to the extent feasible, include tracking of the hazard location and magnitude over time, control of movement into the hazard area, rotation of assets, and tracking of personnel locations and movement in the vicinity. If avoidance of hazards is impractical, exposure should be kept as low as reasonably achievable.

\subsubsection{Operational Disease Control}

1. A contagious disease outbreak during military operations, whether through exposure of military personnel to naturally occurring disease or through the deliberate use of contagious biological warfare agents, must be managed and controlled in order to maintain operational effectiveness and limit casualties. Contagious disease control is accomplished by mitigating individual susceptibility through the use of medical countermeasures, as discussed above, and by preventing the exposure of susceptible personnel to the disease. Medical support personnel will provide recommendations for commanders on the implementation and sustainment of physical control measures designed to prevent exposure; these measures collectively are termed Restriction of Movement (RM). RM should be consistent with any limitations imposed by host nation law, treaty obligations, or agreements/arrangements between the parties.

2. RM controls the spread of contagious disease by restricting contact between healthy groups of personnel and those who have, or are suspected of having, 
contracted the disease. Medically, there are two types of RM: isolation and quarantine. Isolation means the separation of an individual known or suspected to be infected from a healthy population, while quarantine means the confinement and active continued health surveillance of an individual who is suspected of having been exposed to an infectious agent, until it is determined that they are free of infection.

3. Personnel covered by RM do not necessarily need to be removed from the operation. Wherever possible it should be implemented in such a way as to allow them to continue their mission.

4. Any decision making process resulting in the implementation of RM should also include the generation of criteria for lifting RM. These exit criteria will be based on the typical incubation period following exposure for the disease caused by the agent.

5. When outbreaks of contagious disease occur among deployed military personnel, whether natural or induced, there is a risk of parallel outbreaks occurring among civilians or other military forces operating within the JOA and spreading outside the boundaries of the host nation. In such circumstances, the commander, with the assistance of the medical advisor, should coordinate notification of infectious disease information with appropriate national organizations and the World Health Organization, in accordance with International Health Regulations. In such circumstances, the commander may also be asked to support national and international efforts to contain the outbreak and protect public health.

\subsubsection{Casualty Decontamination}

1. Casualty decontamination reduces the threat of continued or increasing contamination-related injury to contaminated individuals, as well as limiting exposure to medical support personnel and otherwise unexposed casualties. Casualty decontamination will have to be accomplished as the operation and casualty load allows. Decontamination and triage of CBRN casualties will obviously vary with the situation and the contaminant. For most CBRN exposures, decontamination should be given priority over treatment or stabilization of a casualty, as the latter can often be delayed without putting the casualty at additional risk. In other cases, such as radiologically contaminated casualties, immediate injuries should be addressed prior to decontamination because the risk to medical personnel is minimal. Trained and qualified triage personnel should determine priority of treatment and decontamination. MTFs supporting operations in potential CBRN environments must establish appropriate procedures for making these triage decisions.

2. Within the theatre, decentralization of casualty decontamination is necessary. 
Casualties must not be forced to wait at central points for decontamination. Casualty decontamination is different from other personnel decontamination procedures: it is a complex and labour-intensive process, and casualties going through decontamination also have medical conditions that must be managed.

3. In some NATO nations, units are primarily responsible for decontaminating personnel under their command as soon as possible and, for those who become casualties, prior to moving them to MTFs. Operational circumstances may, however, prevent them from doing so. As this could have a serious impact on the command's ability to maintain uncontaminated medical facilities, all medical units should have readily available, and be proficient in the use of, the necessary decontamination equipment and procedures for casualty decontamination.

4. There must be adequate medical staff and supporting units tasked to support operation and manning of both the casualty decontamination site areas and the supported MTF. Medical personnel are needed for triage operations and for providing treatment of life- or limb-threatening conditions prior to and during decontamination. Casualty decontamination areas should be close enough to the supported MTF so that the decontaminated casualties can be easily transported to the MTF by designated clean ambulances or other vehicles.

5. Casualty decontamination follows a specified process, although there may be national differences in equipment and procedures. AMedP-7.1 describes methods and procedures for removal of external, internal, and wound contamination It also provides a list of common capabilities that all casualty decontamination sites should have to promote interoperability across nations.

6. Decontamination and collective protection following CBRN incidents are essential if MTFs are in a contaminated area. The commander, with advice from the medical advisor, must consider MTF needs when establishing priorities for allocating decontamination assets.

\subsubsection{Cordons}

When a CBRN hazard cannot be avoided, measures must be taken to manage the hazard so as to minimize the risk to responders and mitigate the effects of the hazard on casualties and exposed personnel. One such measure is the establishment of cordons in the vicinity of the hazard to control and monitor entry to and exit from the area. AMedP-7.1 provides a concept for the use of cordons to create concentric zones of increasing permissiveness based on the nature of the hazard, and identifies casualty management activities appropriate to each designated zone 


\subsection{TRIAGE}

AMedP-7.1 provides general and specific guidance on triage of CBRN casualties. The same established triage categories will be used for CBRN casualties as are now used for conventional casualties, providing consistency for medical planning. This also allows medical personnel to compare priorities between conventional and CBRN casualties where there may be multiple casualty types or incidents.

\subsection{CBRN MASS CASUALTY}

1. Attacks or accidents involving CBRN agents may produce mass casualties, particularly those at the upper end of the CBRN incident scale. In the hours and days immediately following a CBRN incident, MTFs can be overwhelmed with casualties that exceed their capacity, creating a MASCAL situation. In this case, the focus of treatment shifts from meeting the needs of each casualty to doing the greatest good for the greatest number. With this in mind, the JFC, supported by the medical advisor, establishes medical support priorities for treatment of mass casualties. MTF commanders are responsible for planning and training to cope with a MASCAL situation in line with the established joint force priorities.

2. STANAG 2879, Principles of Medical Policy in the Management of a Mass Casualty Situation, includes consideration regarding the modification of triage classifications, revised strategies for casualty movement, augmentation of medical capabilities, and alternate standards of care. In a CBRN MASCAL situation, MTF commanders and medical staff should consider consolidating contaminated personnel to certain hospitals or areas, augmentation of medical resources, or reallocation of medical resources to better manage casualties.

\subsubsection{CBRN MASCAL PIan}

MTFs should have a basic CBRN MASCAL plan that can be modified to meet varying situations. The MASCAL plan must be clearly defined and sufficiently detailed for understanding at all levels. It should be coordinated with MTFs at higher and lower levels of care and approved by the commander. It must be practiced at regular intervals and executable at the appropriate level.

\subsection{COMBAT AND OPERATIONAL STRESS CONTROL}

1. CBRN environments may add to the frequency or severity of combat stress. Symptoms of combat stress disorder may include poor concentration, confusion, low morale, insomnia, fear, and anxiety. In severe cases of combat stress disorder, individuals may feel depressed or suicidal, and exhibit slower reaction times. 
2. Prevention of stress casualties and control of combat and operational stress is a command and leader responsibility. Medical support and other personnel at all levels play important supporting roles. A coordinated program must be planned for the prevention, treatment, and return to duty of combat stress reaction casualties. Active education, training, and prevention programs assist with controlling stress and preparing unit leaders and medical support personnel to identify and manage stress reactions in units. The use of combat and operational stress control teams is essential in preparing for and responding to CBRN incidents. AJP-4.10 discusses combat stress training and stress control techniques.

3. Additionally CBRN incidents may generate confusion, panic, and hysteria. Commanders should coordinate with public affairs personnel in order to quickly and effectively communicate agent risk and response information to personnel in order to avoid confusion and hysteria.

4. Casualties who exhibit no symptoms but have a heightened level of anxiety (the "worried well") may also present at MTFs. The worried well may far outnumber actual symptomatic casualties. In CBRN incidents this problem may be compounded by the delay between exposure and onset typical of many agents, and the difficulty in determining who among the population at risk has been exposed.

5. In addition, uninfected and unexposed casualties may exhibit physical symptoms that are psychogenic only (the "worried sick"). Medical planning staff should consider potential strategies and associated requirements to reduce the impact of the worried well/worried sick on treatment facilities. Strategies for managing the worried well/worried sick might include triage, medical evaluation, counselling, psychological care, public information and media relations. 


\section{CHAPTER 6 MEDICAL EVACUATION}

1. STANAG 2546, AJMedP-2, Allied Joint Doctrine for Medical Evacuation, describes the concept, policy, and assets used for Allied Medical Evacuation (MEDEVAC) operations. The conduct of Allied MEDEVAC operations where feasible allows economies of scale, effective operational management and timely and unhindered intervention across the JOA. Typically, nations are responsible for the transport of casualties from the point of wounding to the initial MTF and for the subsequent evacuation of casualties from the JOA to the home nation. Movement of casualties between different MTFs is, however, a National/Multinational/Force/Lead Nation responsibility, and hence is the focus of both AJMedP-2 and this section of AJMedP-7.

2. All of the key considerations discussed above in planning for medical support to CBRN defence operations are significant from the perspective of medical evacuation. The number of casualties that must be managed may far exceed conventional planning estimates, and they may present within a narrow time window. Moreover, the utilization of MEDEVAC assets may be significantly slowed in a CBRN environment, reducing the overall capacity of the system. Casualties may be contaminated or contagious, requiring decontamination or specialized equipment and procedures for contamination control. MEDEVAC operations may need to be conducted in contaminated areas, generating requirements for both individual and collective protection and decontamination for personnel, equipment and vehicles.

\subsection{MEDICAL EVACUATION POLICY AND OPERATIONS IN A CBRN ENVIRONMENT}

1. Movement of casualties is not just transportation to a suitable MTF but is part of a continuum of casualty treatment and care, and is therefore, a medical responsibility. Whenever possible the MEDEVAC system has to ensure that each casualty is brought to a MTF that is capable of coping with his/her illness or injury. At no point in the chain of evacuation must the level of care be reduced below that received at the previous MTF.

2. Should the CBRN environment cause a mass casualty situation, lateral or skip movement of casualties may be required to maintain the required level of care and maximize the efficiency of MTF operations in the JOA. The anticipated progression of CBRN injuries and illnesses may also dictate nonlinear movement of casualties through the evacuation chain.

3. MEDEVAC is a component of medical regulating, which in turn is the process 
of directing, controlling and coordinating the transfer of casualties. This means regulating from point of wounding or onset of disease through successive MTFs, in order to facilitate the most effective use of medical treatment and evacuation resources and to ensure that the casualty receives appropriate care in a timely manner. Medical regulating is especially relevant in a multinational environment where casualties of different nations are required to be returned to the national medical chains at the most appropriate point in their clinical management.

4. Medical regulating in a CBRN environment may require changes to ongoing MEDEVAC operations. The presence of contaminated areas in particular will effect consideration of the movement of casualties out of or through contaminated areas. Every effort should be made to limit the number of assets and people that become contaminated due to their movement. To that end, some portion of MEDEVAC assets may be dedicated for use within designated contaminated areas, with the remainder dedicated to transporting casualties between MTFs in clean areas.

5. The decontamination of casualties before evacuation will help limit the spread of contaminants throughout the MEDEVAC chain. In cases where decontamination of casualties cannot be done, transport should be limited to movement that is essential to provide casualty care.

6. Different types of CBRN incidents will generate different operational conditions, restrictions, and requirements. MEDEVAC operations will be affected in the same manner as other medical and non-medical operations. AJP-3.8, Allied Joint Doctrine for Chemical, Biological, Radiological, and Nuclear Defence, provides guidance for the conduct of operations in various hazard environments.

7. Commanders must weigh the risk and consequences of CBRN exposure in making decisions regarding the conduct of MEDEVAC operations in contaminated areas, Annexes A and C of AMedP-8 can be used to assess the impact of exposure to specific agents on the probability and severity of injury over time.

8. Other components of the medical regulating process may require modification to maintain the balance between MEDEVAC assets and the treatment capability available at each Role. Deployed MTFs may need to be resituated to facilitate contamination avoidance and provide more efficient transport routes from designated CBRN contamination zones. Reallocation and movement of medical personnel and equipment among MTFs may further improve the efficiency of medical operations challenged by large numbers of casualties and large areas of contamination.

9. Theatre Holding Policy is a command decision indicating the maximum length of time (days) that a casualty will be allowed to remain in the theatre for treatment, recovery and return to duty. Theatre holding policy is the key to balancing the treatment capability available at each Role against the MEDEVAC assets with 
regard to capabilities and capacities required to provide casualties with the best possible medical care.

10. In the aftermath of a CBRN incident, theatre holding policy may need to be extended in response to both the number and type of resulting casualties. In some cases, large numbers of casualties may have injuries or illnesses of moderate severity and would be expected to return to duty soon after the established maximum length of stay. In others, economies of scale in the provision of treatment may best be achieved if casualties requiring highly specialized care are treated at a common location; these locations may be within the JOA. Finally, contagious disease patients may be subject to RM, and thus remain in theatre for an extended period of time. In addition, movement of contagious disease patients out of theatre may be affected by World Health Organization efforts to prevent spread of the disease across international borders, under the auspices of the International Health Regulations.

11. Host nation and multinational partners may have concerns about exposing their civilian population to contamination or contagion while CBRN casualties are in transport within their borders. Transportation of these casualties will require close coordination and cooperation between Joint Force Commanders and host nation authorities. In some cases, MEDEVAC (particularly aeromedical evacuation) may only be accomplished if overflight and landing rights are permitted by the host nation.

\subsection{MEDICAL EVACUATION ASSETS IN A CBRN ENVIRONMENT}

In a CBRN environment, contaminated casualties and those infected with contagious biological agents should not normally be transported by any means without first being decontaminated or cleared for transport. In rare cases, movement may be essential to preserve life, limb or eyesight or to maintain operational capabilities and on these occasions every effort must be made to prevent the spread of contamination during movement. When allocating MEDEVAC assets to evacuation routes within contaminated areas, consideration should be given to asset type, its associated requirements for decontamination, and the availability of decontamination resources.

\subsubsection{Aeromedical Evacuation of CBRN Casualties}

1. Aeromedical evacuation provides transportation to and between MTFs after initial casualty stabilization and treatment. Most casualties should therefore be decontaminated prior to entering the aeromedical evacuation system. Procedures implemented during aeromedical evacuation should include precautions to avoid aircraft contamination, as decontamination of an aircraft is often a challenging task. 
In the event casualties cannot be decontaminated, the commander will identify the requirement to move contaminated or contagious casualties and apply available contamination control measures when possible.

2. A CBRN environment and the resulting number and type of casualties may strain the capacity of dedicated military airlift. In addition to overwhelming numbers of casualties, the potential requirements for specialized medical equipment, such as ventilators and positive pressure, or the need for casualty isolation may further reduce the number of casualties that any given aircraft can transport. In these circumstances, aircraft of opportunity or multinational and civilian aircraft may need to be integrated into aeromedical evacuation operations.

\subsubsection{Movement of Contagious Disease Casualties}

The basic principles of medical evacuation of casualties with infectious diseases are the same as those for any medical condition. For some acute contagious conditions it may be appropriate to delay casualty movement until recovery, when the individual becomes asymptomatic and poses minimal risk of contagion. If circumstances dictate that casualty movement is essential, then this can be undertaken provided that appropriate infection control measures are adopted.

\subsubsection{Specialized National Evacuation Capabilities}

Some nations have specialized evacuation capabilities that may be of particular utility in a CBRN environment. Some nations maintain air transportable isolators, such as the Vickers unit; these are self-contained units that can be placed into an aircraft to provide an infection barrier and enable safe movement of a highly contagious patient without endangering the medical team or the aircraft crew. Critical Care Air Support Teams (CCAST) are specialist teams organized by individual nations with intensive care expertise for aeromedical evacuation of critically ill casualties, including those that require ventilation. Though typically limited in capacity, and hence of limited utility in a MASCAL environment, planners should be aware of these capabilities and have procedures in place to coordinate their use if required. 


\section{CHAPTER 7 SUSTAINMENT OF MEDICAL OPERATIONS}

1. Among the key considerations discussed above in planning for medical support to CBRN defence operations, all of them could contribute to difficulties in sustaining medical operations:

a. The large number of casualties that could result from CBRN could overwhelm the capabilities of the MTFs;

b. MTFs designed, staffed and supplied to respond to the types and numbers of casualties normally managed in a military medical support system may not have the proper amounts or types of materials and capabilities required to respond to casualties from a CBRN incident;

c. Contaminated or contagious CBRN casualties may constitute a significant hazard to the medical personnel and facilities charged with caring for them;

d. MTFs operating in contaminated areas, or with restrictions that limit movement of personnel and materiel, may not be able to effectively manage the casualty flow into, within, and out of the MTF; and

e. The medical support required for CBRN casualties may be disproportionate to that required for conventional casualties, but care for conventional casualties must continue as well as for CBRN casualties.

2. Planning for and organizing medical support under plausible CBRN environments can help ameliorate these difficulties and promote sustainment of medical operations. Planning for sustainment of medical operations in a CBRN environment must consider the location and operation of MTFs, the logistical support of those MTFs, and the effective use of preventive medicine capabilities.

\subsection{FACILITIES MANAGEMENT}

1. MTF commanders will prepare measures to sustain critical operations and recover essential operations following a CBRN incident. Commanders must identify sites where mitigation might nullify or degrade the impact of a CBRN incident, and should identify the missions and facilities that are most critical to recover first should an incident occur. Measures to sustain critical operations and recover essential operations should reduce potential degradation caused by a CBRN incident. Critical missions must be sustained and recovery of essential military operations should be swift.

2. CBRN defence standard operating procedures must be prepared during pre- 
deployment. Once deployed, the joint force must exercise, train, validate, and adjust, if necessary, these SOPs to meet the conditions encountered in-theatre. Evaluations must also be made to ensure that general operating procedures are workable in a CBRN environment. Procedures must be established and practiced to ensure casualties are decontaminated before entering medical treatment facilities where possible; to augment existing medical treatment facilities in response to increased and uneven medical workload across the JOA; and to assist medical administration and management during an incident.

3. The proper planning, location and management of facility operations will facilitate continuity of medical support that will be required for conventional casualties as well as for CBRN casualties. Whenever possible, an MTF should be located such that it is maximally protected from a CBRN incident. No matter where the MTF is located, treatment providers must still have physical protection available to them and should be prepared to implement contamination avoidance measures as needed.

4. Civilian casualties may be a significant problem in populated areas. Planning for medical support under CBRN conditions should include to what degree and under what conditions military medical support is provided to civilians. Medical support may be required to assist in treating civilian casualties when the civilian medical resources become overwhelmed and inundated with casualties. Demands for military medical support to neighboring civilian populations following a CBRN incident may be substantial, especially in areas with a concentration of very young, very old, and other individuals already suffering from underlying disease or other forms of weakening stress. During the planning phases of the operation, in consultation with the medical advisor, and as informed by the results of CBRN risk assessments, the JFC should establish the scope of care to be rendered to civilian populations. The level of medical care available to civilians should be commensurate with levels of medical infrastructure deployed and established to provide the care envisioned.

5. Medical support operations at MTFs should avoid diversion of medical specialists to nonmedical tasks. Whenever possible, in line with JFC priorities and assets, augmentation should be made available from nonmedical sources of support to perform tasks such as decontamination, physical security, and maintenance of contamination-free areas and collective protective shelters.

6. Depending on the type of CBRN incident and the intensity of ongoing conventional combat, it is possible that medical support operations in a CBRN environment may be faced with the additional challenge of degraded infrastructure. Roads may be impassable and clean water and power may be unavailable outside of the MTF. Planners must consider the potential for the loss of infrastructure and logistical support and prepare for the sustainment of medical support and ensure continuity of care during a CBRN incident. 


\subsection{MEDICAL CBRN LOGISTICS}

1. The commander is responsible for providing MTFs with adequate logistic support in theatre, including damage control, relocation, and resupply, in line with JFC priorities and assets. The proper planning and management of medical supplies, waste, and contamination will facilitate continuity of the medical support that will be required for conventional casualties as well as for CBRN casualties. This planning should be based on the assessed CBRN risk and plausible CBRN environments to ensure that medical support is tailored to meet mission requirements.

2. Procedures must be established and practiced to ensure the timely and appropriate distribution and administration of prophylactic or preventive medical pretreatment measures to counter effects of possible CBRN hazards; in compliance with the given operational priorities and established international and national guidelines; to ensure casualties are decontaminated before entering medical treatment facilities where possible; to collect medical specimens as required for laboratory analysis and identification; and to distribute medical supplies.

3. The logistic staff plays an important part in ensuring that medical facilities are able to carry out their primary tasks. It is their responsibility to provide many of the critical needs of a medical facility, which may include:

a. Power, fuel, laundry, rations, water, maintenance of vehicles, general supply items lost due to contamination, and accommodation;

b. The provision of vehicles for the movement of MTFs, if required;

c. The provision of host nation support or local contracting for the supply of services to medical facilities; and

d. The employment of civil labor.

4. MTFs and logistic units must be prepared to manage medical support items being provided by well-meaning individuals and organizations that may not be appropriate for consequence management.

\subsubsection{Management of Human Remains}

1. The JFC has the responsibility to search, recover, tentatively identify, and evacuate human remains from the area of operations. This is a logistical mission, but not a medical mission. To complete this task, the JFC may establish a mortuary affairs decontamination collection point (MADCP). The MADCP is an operational element under the oversight of the mortuary affairs office, and is manned by specialized mortuary affairs personnel. 
2. Human remains that have been properly decontaminated and rendered safe may be transported in accordance with national policy and procedures. However, contaminated human remains should remain in place and not be transported until such time as the methods for returning contaminated human remains safely have been established by the Joint Force Commander. 


\section{ANNEX A ACRONYMS AND ABBREVIATIONS}

$\underline{\mathbf{C}}$

C2 Command and Control

CBRN Chemical, Biological, Radiological, and Nuclear

CCAST Critical Care Air Support Team

COLPRO Collective Protection

$\underline{D}$

DHSC Deployment Health Surveillance Centre

$\underline{F}$

FHP Force Health Protection

FP Force Protection

!

IPE Individual Protective Equipment

$\underline{\mathbf{J}}$

JFC Joint Force Commander

JOA Joint Operations Area

$\underline{M}$

MADCP Mortuary Affairs Decontamination Collection Point

MASCAL Mass Casualty

MEDEVAC Medical Evacuation

MEDICS Medical Information and Coordination System

MEDINT Medical Intelligence

MRIIT Medical Radiological Incident Investigation Team

MTF Medical Treatment Facility

$\underline{\mathbf{R}}$

RDOIT Rapidly Deployable Outbreak Investigation Team 
ANNEX A TO

AJMedP-7

RM Restriction of Movement

$\underline{\mathbf{S}}$

SA Situational Awareness

I

TIM Toxic Industrial Materials 


\section{ANNEX B}

\section{REFERENCES}

STANAG 2437 Allied Joint Doctrine, AJP-01

STANAG 2182 Allied Joint Doctrine for Logistics, AJP-4

STANAG 2228 Allied Joint Medical Support Doctrine, AJP-4.10

STANAG 2451 Allied Joint Doctrine for CBRN Defence, AJP-3.8

STANAG 2546 Allied Joint Doctrine for Medical Evacuation, AJMedP-2

STANAG 2547 Allied Joint Doctrine for Medical Intelligence, AJMedP-3

STANAG 2561 Allied Joint Medical Force Health Protection, AJMedP-4

STANAG 2136 Requirements for Water Potability during Field Operations and in Emergency Situations, AMedP-4.9

STANAG 2461 The Medical Management of CBRN Casualties, AMedP-7.1

STANAG 2478 Medical Support Planning for Nuclear, Biological and Chemical Environments, AMedP-41

STANAG 2520 CBRN Defence Standards for Education, Training and Evaluation, ATP-3.8.1 Vol III

STANAG 2521 CBRN Defence on Operations, ATP-3.8.1 Vol I

STANAG 2522 Specialist CBRN Defence Capabilities, ATP-3.8.1 Vol II

STANAG 2528 Allied Joint Doctrine for Force Protection, AJP-3.14

STANAG 2529 Rapidly Deployable Outbreak Investigation Team (RDOIT) for Suspected Use of Biological Warfare Agents, AMedP-7.7

STANAG 2535 Deployment Health Surveillance, AMedP-4.1

STANAG 2551 Regulations for Establishment and Employment of MRIIT (Medical Radiological Incident Investigation Teams), AMedP-7.4

STANAG 2553 NATO Planning Guide for the Estimation of CBRN Casualties, AMedP-8 
STANAG 2560 Medical Evaluation Manual, AMedP-27

STANAG 2873 Concept of Operations of Medical Support in Chemical, Biological, Radiological, and Nuclear Environments, AMedP-7

STANAG 2879 Principles of Medical Policy in the Management of a Mass Casualty Situation

STANAG 2954 Training of Medical Personnel for CBRN Force Protection, AMedP-44

STANAG 4632 Deployable NBC Analytical Laboratory

STANAG 4701 Handbook for the Sampling and Identification of Chemical, Biological and Radiological Warfare Agents, AEP-66 


\section{ANNEX C}

GLOSSARY

This lexicon is provided to help with the understanding of this AJMedP. However, it is not the full and definitive reference of NATO medical terminology for which the reader is referred to the up-to-date NTMS (NATO Terminology Management system) or (Not updated) STANAG 2409 - AMedP-13 - NATO Glossary of Medical Terms and Definitions.

CASUALTY: With regard to the personnel system, a person who is lost to an organization by reason of having been declared dead, wounded, injured, diseased, detained, captured or missing.

CBRN AGENT: A generic term used for substances in solid, liquid, aerosolized or gaseous forms that are designed to incapacitate or kill a person. (NOT NATO AGREED)

CHEMICAL, BIOLOGICAL, RADIOLOGICAL AND NUCLEAR DEFENCE (CBRN DEFENCE): The plans, procedures and activities intended to contribute to the prevention of chemical, biological, radiological and nuclear incidents, to protect forces, territories and populations against, and to assist in recovering from, such incidents and their effects.

CBRN INCIDENT: Any occurrence, resulting from the use of CBRN weapons or devices; the emergence of secondary hazards arising from counter-force targeting; or the release of toxic industrial material into the environment, involving the emergence of CBRN hazards or effects. Note: CBRN incidents are either 'suspected' or 'confirmed' as appropriate to the situation.

MEDICAL EVACUATION: The medically supervised process of moving any person who is wounded, injured or ill to and/or between medical treatment facilities as an integral part of the treatment continuum.

FORCE PROTECTION: All measures and means to minimize the vulnerability of personnel, facilities, equipment and operations to any threat and in all situations, to preserve freedom of action and operational effectiveness of the force.

FORCE HEALTH PROTECTION: A subset of force protection, force health protection is the sum of all efforts to reduce or eliminate the incidence of disease and non-battle injuries to enhance operational health readiness and combat effectiveness. (NOT NATO AGREED)

MEDICAL INTELLIGENCE: Intelligence derived from medical, bio-scientific, epidemiological, environmental and other information related to human or animal 
health. This intelligence, being of a specific technical nature, requires informed medical expertise throughout its direction and processing within the intelligence cycle.

JOINT FORCE COMMANDER: A general term applied to a commander (e.g. Commander of Allied Joint Force (COMAJF)) authorized to exercise command authority or operational control over a joint force. (NOT NATO AGREED)

JOINT OPERATIONS AREA (JOA): A temporary area defined by the Supreme Allied Commander Europe, in which a designated joint commander plans and executes a specific mission at the operational level of war. A joint operations area and its defining parameters, such as time, scope of the mission and geographical area, are contingency- or mission-specific and are normally associated with combined joint task force operations.

MASS CASUALTY (MASCAL) SITUATION: A mass casualty situation is one in which an excessive disparity exists between the casualty load and the medical capabilities locally available for its management. Any number of casualties produced in a relatively short period of time which overwhelms the available medical and logistic support capabilities. (NOT NATO AGREED)

MEDICAL ADVISOR: The senior medical staff officer in a formation headquarters responsible for ensuring that the commander and his staff are properly aware of the health and medical implications of their actions and any issues connected to the operation. The Medical Advisor may also be the Force or Theatre Medical Director. (NOT NATO AGREED)

MEDICAL COUNTERMEASURES: Those medical interventions designed to diminish the susceptibility of personnel to the lethal and damaging effects of chemical, biological and radiological hazards and to treat any injuries arising from exposure to such hazards.

PREVENTIVE MEDICINE: The services that are concerned with identifying, preventing and controlling acute and chronic communicable and non-communicable diseases and illnesses with food and environmental hygiene, and vector control. (NOT NATO AGREED)

RESTRICTION OF MOVEMENT: A measure for controlling the spread of a contagious disease by by restricting contact between healthy groups of personnel and those who either have, or are suspected of having, contracted a contagious disease.

(THEATRE) HOLDING POLICY: A command decision which sets the maximum period a hospitalized convalescing casualty will be kept in the theatre of operations awaiting recovery and return to duty. It is a control measure to ensure that sufficient 
hospital capacity is retained for anticipated surges in battle casualties or illnesses. (NOT NATO AGREED)

TRIAGE: The evaluation and classification of wounded for purposes of treatment and evacuation. It consists of the immediate sorting of patients according to type and seriousness of injury, and likelihood of survival, and the establishment of priority for treatment and evacuation to ensure medical care of the greatest benefit to the largest number. 
AJMedP-7 (A)(1) 


\section{REPORT DOCUMENTATION PAGE}

Public reporting burden for this collection of information is estimated to average 1 hour per response, including the time for reviewing instructions, searching existing data sources, gathering and maintaining the data needed, and completing and reviewing this collection of information. Send comments regarding this burden estimate or any other aspect of this collection of information, including suggestions for reducing this burden to Department of Defense, Washington Headquarters Services, Directorate for Information Operations and Reports (0704-0188), 1215 Jefferson Davis Highway, Suite 1204, Arlington, VA 22202-4302. Respondents should be aware that notwithstanding any other provision of law, no person shall be subject to any penalty for failing to comply with a collection of information if it does not display a currently valid OMB control number. PLEASE DO NOT RETURN YOUR FORM TO THE ABOVE ADDRESS.

1. REPORT DATE (DD-MM-YY)

31 July 2014

2. REPORT TYPE

3. DATES COVERED (From - To)

4. TITLE AND SUBTITLE

NATO Allied Joint Medical Publication 7: Allied Joint Medical Doctrine for Support to Chemical, Biological, Radiological, and Nuclear (CBRN) Defensive Operations, Final Draft

5a. CONTRACT NO.

DASW01-04-C-0003

5b. GRANT NO.

5c. PROGRAM ELEMENT NO(S).

6. AUTHOR(S)

Carl A. Curling, Julia K. Burr

5d. PROJECT NO.

5e. TASK NO.

CA-6-3079

5f. WORK UNIT NO.

7. PERFORMING ORGANIZATION NAME(S) AND ADDRESS(ES)

Institute for Defense Analyses

8. PERFORMING ORGANIZATION REPORT NO.

4850 Mark Center Drive

Alexandria, VA 22311-1882

9. SPONSORING I MONITORING AGENCY NAME(S) AND ADDRESS(ES)

Office of the Surgeon General of the Army Joint Requirements Office for CBRN Defense ATTN: DASG-HCO (G-34)

7700 Arlington Blvd, Ste 5143

(JRO-CBRND)

Falls Church, VA 22042-5143

Joint Chiefs of Staff/J-8

8000 Joint Staff Pentagon, Room 1D958

Washington, DC 20318-8000

IDA NS P-5153

10. SPONSOR'S I MONITOR'S ACRONYM(S)

OTSG

11. SPONSOR'S I MONITOR'S REPORT NO(S).

\section{DISTRIBUTION / AVAILABILITY STATEMENT}

Approved for public release; distribution is unlimited.

\section{SUPPLEMENTARY NOTES}

\section{ABSTRACT}

Chemical, biological, radiological and nuclear $(\mathrm{CBRN})$ weapons produce battlefield conditions not found in conventional warfare. The presence of contaminants, the types and times of injuries, and the scale of CBRN weapon effects are such that conventional planning processes will be inadequate to address the CBRN challenge. The consideration of the unique aspects of CBRN conditions on the medical planning process is such that a clearly articulated doctrine is required to enable medical support to CBRN defensive operations.

The aim of AJMedP-7, Allied Joint Medical Doctrine for Support to CBRN Defensive Operations, is to bridge the foundational medical support doctrine in AJP 4.10, Allied Joint Medical Support Doctrine, and the specific requirements for medical support to CBRN defensive operations now found within advisory and technical publications. This publication is principally for use by North Atlantic Treaty Organization (NATO) commanders and their medical staffs in the planning and conduct of medical support operations for which there is an assessed risk of intentional or accidental use of CBRN substances.

15. SUBJECT TERMS

CBRN, Medical, NATO Medical Doctrine, AJMedP-7

16. SECURITY CLASSIFICATION OF:

\begin{tabular}{|c|c|c|}
\hline a. REPORT & b. ABSTRACT & c. THIS PAGE \\
$\mathrm{U}$ & $\mathrm{U}$ & $\mathrm{U}$ \\
\hline
\end{tabular}

17. LIMITATION 18. NO. OF PAGES 19 a.NAME OF RESPONSIBLE PERSON

OF ABSTRACT

UU
66 MAJ H. Michael Stewart, Jr.

19b. TELEPHONE NUMBER (Include Area Code)

703-681-8188 
